\title{
Society News
}

\section{AMERICAN ACADEMY OF SPORTS PHYSICAL THERAPY (AASPT)}

After a successful Virtual Team Concept 2020 Conference (TCC) we'd like to take a moment to say thank you to all our conference attendees, speakers, presenters, and especially our sponsors. All of you made this event possible and a great success! We couldn't have done it without you. We are looking forward to our next TCC being in person where we can see everyone come together, sharing in opportunities and networking.

As we enter this new year, we'd like to highlight CSM (Combined Sections Meeting) 2021 that will be happening the entire month of February. Over the years, CSM has become the definitive annual gathering for the physical therapy profession. The American Physical Therapy Association's (APTA's) intention is that it remains so in 2021. In fact, by holding the event virtually they are hoping to generate participation from first-time attendees who can take advantage of the more inclusive format, and we hope that leads potential members to join the APTA community. To learn more about CSM, visit apta.org/csm.

As APTA is celebrating 100 years as a member association, we are beyond honored and thankful to be a part of an

organization and community with members all across the globe. Cheers to another 100 years!

To learn more about AASPT's upcoming events, learning opportunities, and news, please visit aaspt.org. We look forward to continue servicing sports physical therapists throughout this year and fostering a community of support and opportunity.

\section{AMERICAN MEDICAL SOCIETY FOR SPORTS MEDICINE (AMSSM)}

\section{AMSSM Annual Meeting (Hybrid)_Come Together: Sports Medicine for Everybody}

AMSSM is planning for a hybrid format for the 2021 Annual Meeting (a portion of attendees meeting in person and a portion of attendees streaming the conference virtually). The meeting is scheduled to take place from April 13 to 18, 2021, including an in-person option in San Diego with all necessary health and safety precautions as well as a virtual live-stream option.
Our theme is "Come Together: Sports Medicine for Everybody." The meeting will feature outstanding speakers from around the world who will teach, challenge, and inspire us to treat every patient as an athlete.

On April 12, 2021, the AMSSM Collaborative Research Network will host a scientific summit on physical activity and exercise medicine. The summit will focus on broad and effective integration of physical activity promotion and exercise medicine within sports medicine.

The 2021 Annual Meeting brochure and online registration will be available in mid-January by visiting AMSSM's website at www.amssm.org.

\section{New \$10,000 Underrepresented} Minority Research Grant Opportunity

The AMSSM Foundation is providing a new research grant opportunity for underrepresented minority research members. The AMSSM Minority Research Grant aims to provide research opportunities specifically for historically underrepresented minorities in biomedical research to advance representation across diverse backgrounds and promote health equity in sports medicine research.

The AMSSM Foundation and AMSSM Research Committee seek to award 1 grant worth $\$ 10,000$ for a grant cycle length of 1 year. The due date for this grant will be February 15, 2021, and this grant replaces the previous AMSSM-ACSM Clinical Research Grant.

Complete eligibility criteria and the full RFP (request for proposal) are available on the AMSSM website at https://www.amssm.org/Research.html.

\section{Educational Video Resources Available for Free on AMSSM YouTube Channel}

In the past few months, AMSSM has launched 2 new video series that provide ongoing educational content relating to fellows education and sports ultrasound.

The National Fellow Online Lecture Series takes place every week and serves as an adjunct to individual programs' educational programming. These lectures provide fellows with direct access to educational experiences with experienced AMSSM members and, at times invited guest experts in a variety of formats and in an effort to assist in Certificates of Added Qualification (CAQ) Exam preparation. 
The Sports Ultrasound Committee also conducts the Sports Ultrasound Case Presentation Series, which will take place every other week and feature live video presentations from AMSSM members.

All past talks are available on the AMSSM YouTube channel, and AMSSM members are invited to watch these lectures live.

\section{AMERICAN ORTHOPAEDIC SOCIETY FOR SPORTS MEDICINE (AOSSM)}

\section{AAOS/AOSSM/AANA 2021 Sports Medicine Cases and Controversies Webinar}

In this webinar on February 2, 2021, we will take the most highly rated topics from the annual AAOS/AOSSM/AANA Sports Medicine Ski meeting (normally held in Park City, Utah), including case-based learning with the experts on management of the irreparable rotator cuff tear, revision anterior cruciate ligament (ACL) decision making and treatment, and rehabilitation options for the athlete who struggles to return to play following ACL reconstruction. Learn more at sportsmed.org.

\section{Specialty Day 2021}

Join us virtually on March 17 to 18, 2021. The 2-day program will be hosted by AANA and AOSSM. Learn more and register at sportsmed.org.

\section{Nashville 2021 Here We Come!}

We encourage you to visit our 2021 Annual Meeting website at sportsmed.org/AM2021 as details are being posted frequently, including Registration and Housing news and Exhibitor and Sponsor opportunities. The 2021 Annual Meeting will bring together core components of our programming, while exploring important new topics through new Game Changer Sessions and the highly anticipated Sports Health Symposium.

\section{Stay Game-Ready With AOSSM's Playbook!}

Access AOSSM's current and constantly growing eLearning opportunities, including on-demand CME and our Surgical Video Library to excel in the game! View at sportsmed.org/playbook.

\section{Join the Sports Medicine Conversation}

Check out AOSSM on LinkedIn-just search for the American Orthopaedic Society for Sports Medicine to receive regular sports medicine news and updates. You can also see recent member videos and journal updates on our YouTube channels, AOSSM1972 and AOSSM Publishing, and read the latest across our various Facebook and Twitter accounts.

\section{NATIONAL ATHLETIC TRAINERS' ASSOCIATION [NATA]}

Use the Professional Development Center This Reporting Year and Beyond

The year 2021 is a reporting year, and it's never too early to start earning your required continuing education units (CEUs) and evidence-based practice (EBP) CEUs. The NATA Professional Development Center (PDC) offers courses that cover a wide range of topics athletic trainers (ATs) encounter daily. This includes everything from mental health to telemedicine. PDC visitors can filter courses by level, domain, and course format. In addition, NATA members receive 10 free CEU credits that they can use in the PDC through December 31. For more information, visit www.nata.org/professional-development-center.

\section{Get Ready for National Athletic Training Month}

Now is a great time to get ready for National Athletic Training Month (NATM)! Held each March, NATM shines a light on the athletic training profession to help spread awareness about the important work ATs do. NATA offers a variety of resources to help ATs and their community celebrate the athletic training profession. Learn more at www.nata.org/advocacy/publicrelations/national-athletic-training-month.

\section{Read the Latest Sports Medicine Legal Digest}

Stay up to date on the latest risk, liability, and professional responsibility trends in sports medicine by reading NATA's quarterly Sports Medicine Legal Digest, available exclusively to NATA members. The latest edition examines what ATs need to know about changes made to Title IX in 2020 and includes a column from the NATA Professional Responsibility in Athletic Training Committee about the legal side of social media. Read the Sports Medicine Legal Digest at www.nata.org/ nata-legal-digest.

\section{Share Your \#ATsinAction Photos}

NATA is looking for ATs to feature in our marketing and communications efforts. We know that ATs perform so many tasks and duties every day, especially in the midst of the COVID-19 pandemic. ATs in Action authentically depicts ATs doing what they do best-providing exceptional health care to a varied patient population in a host of settings. NATA is actively accepting photos that highlight diversity in ATs, patients, settings, and activities, as well as photos that properly illustrate social distancing and the use of personal protective equipment. Help us tell your story. Learn more and upload your photos at www.nata.org/node/216428. 